\title{
Integrating biocontrol agents with farmer's practice: impact on diamondback moth, Plutella xylostella (Linnaeus) (Lepidoptera: Plutellidae) and cabbage yield
}

\author{
Omprakash Navik ${ }^{1 *}$ D, R. S. Ramya², Richa Varshney², S. K. Jalali², T. M. Shivalingaswamy², R. Rangeshwaran², \\ Y. Lalitha' ${ }^{2}$, Jagadeesh Patil ${ }^{2}$ and Chandish R. Ballal ${ }^{2}$
}

\begin{abstract}
A field trial was conducted in a farmer's field by integrating biocontrol agents, a multiple insecticide tolerant strain (MITs), Trichogramma chilonis and formulation of Bacillus thuringiensis (NBAIR BtG4) with reduced insecticidal spray as a biocontrol-based IPM compared to insecticidal application as a farmer's practice, for the management of the diamondback moth (DBM), Plutella xylostella (Linnaeus) (Lepidoptera: Plutellidae) infesting cabbage. Six T. chilonis releases of 100,000 parasitized eggs $\mathrm{ha}^{-1}$ were applied. Along with parasitoid release, a liquid formulation of $B$. thuringiensis (2\%) was applied after third and fifth releases of T. chilonis. The number of $P$. xylostella larvae were significantly reduced in the field treated with biocontrol-based IPM as compared to farmer's practice after 30 and 45 days after treatment. After the 45 days, the holes on cabbage leaves were 2.2/plant in the field treated with biocontrol, opposed to 8.0 holes per plant were recorded in the farmer's practice filed. Only $7 \%$ of cabbage head damage was recorded in the field treated with biocontrol, whereas, in farmer's practice field, those were $32.2 \%$. The cost-benefit analysis showed that integrating these biological control agents along with a reduced number of insecticidal sprays could reduce DBM population and percent head damage with an eventual increase in the yield.
\end{abstract}

Keywords: Plutella xylostella, Cabbage, Trichogramma, Bacillus thuringiensis, Integrated management

\section{Background}

Cabbage (Brassica oleracea var. capitata L.) is one of the extensively grown vegetable crops in India. Its cultivation is spread across tropical to temperate climatic conditions and constitute the most important component in the diets of various cultures (Shelton 2004). In India, cabbage is grown in an area of $0.39 \mathrm{~m}$ ha with a production of $8.8 \mathrm{MT}$ with an average productivity of $22 \mathrm{tha}^{-1}$ (NHB 2016). The production of healthy and insect pest-free cabbage to fetch a remunerative price in the market, more attention has been paid towards the plant protection measures. Under extensive cultivation, cabbage suffers from the diamondback moth (DBM),

\footnotetext{
* Correspondence: omnavikm@gmail.com

'Division of Germplasm Collection and Characterization, ICAR-National Bureau of Agricultural Insect Resources, P. B. No. 2491, H. A. Farm Post, Bellary Road, Bengaluru 560 024, India

Full list of author information is available at the end of the article
}

Plutella xylostella (Linnaeus) (Lepidoptera: Plutellidae), and leaf webber, Crocidolomia binotalis Zeller (Nagarkatti and Jayanth 1982), that affects the production and quality of the yield. Among them, P. xylostella is the most destructive insect pest of cabbage and even more difficult pest to control. The loss in crop yield caused by this pest varies from 31 to 100\% (Lingappa et al. 2004). Cultivation of crop round the year provides regular availability of host plant that helps DBM to complete 16-20 generations (Talekar and Shelton 1993). The mainstay of control measure under intensified farming is the frequent use of insecticides. The sole reliance on insecticides control of DBM has led a selection pressure that did help in the rapid build-up of resistance to almost all groups of insecticides (IRAC 2017). Development of DBM resistance to relatively selective compounds from the newer insecticide groups also have been reported (Ramya et al. 2016). Moreover, redundant 
use of broad-spectrum insecticides for its control not only increased the cost of production, but also led to environmental pollution through toxic residue (Guo et al. 1999). The worldwide efforts have been made to develop an efficient, integrated pest management approach with the incorporation of non-chemical methods for DBM management (Sarfraz et al. 2005). Egg parasitoids, Trichogramma and Trichogrammatoidea, have been reported for DBM control and were found promising in the management under glasshouse conditions and field studies (Singh and Jalali 1993).

An Austro-Asian origin species, Trichogramma chilonis Ishii, is the most widely used in integrated pest management (IPM) in India against lepidopterous pests of various crops. The development of insecticide tolerant strain has a potential to tolerate the pressure of frequent insecticidal applications by farmers and enables to suppress the insect pest's infestations in farmers' fields (Jalali et al. 2016). However, utilization of T. chilonis in combination with Bacillus thuringiensis $(B t)$ for DBM control was reported in a net house and under laboratory conditions (Singh et al. 2000). Several formulations of $B t$ were evaluated either in the greenhouse or field conditions in the form of dust, wettable powder, or emulsion from different parts of countries against DBM. (Justin et al. 1990 and Asokan and Mohan 1996). However, the research on the combination of these biocontrol agents with farmer's practices has been limited.

Therefore, in the present study, adaptation of the biocontrol-based IPM, using an insecticide tolerant strain of T. chilonis (NBAII-MP-TRI-13) and liquid formulation of $B$. thuringiensis (NBAIR BtG4) for the management of DBM in cabbage field in comparison with farmer's applications of insecticides were assayed.

\section{Materials and methods}

Source of Trichogramma chilonis and Bacillus thuringiensis The multiple insecticide-tolerant egg parasitoid strain, $T$. chilonis (NBAII-MP-TRI-13) was obtained from the Division of Genomic Resources, ICAR-National Bureau of Agricultural Insect Resources (NBAIR), Bengaluru, India, where it is maintained under selection pressure of 5 groups of insecticides (organo-chlorine, organophosphate, synthetic pyrithroid, oxa-dizinon, and spinosyn) for the last 10 years and mass-produced in the Insectary of the Division of Germplasm, Conservation, and Utilization, ICAR-NBAIR, Bengaluru. The parasitoids were mass produced on the eggs of rice grain moth, Corcyra cephalonica Stainton. A liquid formulation of $B$. thuringiensis (NBAIR BtG4) developed in the Division of Genomic Resources, ICAR-NBAIR, Bengaluru, was used for the field experiment.

\section{Insecticides}

The commercial formulations of recommended chemical insecticides for the management of DBM were obtained for field experiment from the local market.

\section{Field trial}

A field experiment was conducted on naturally infested cabbage with DBM in the Chikballapur, Karnataka, located at $\left(13^{\circ} 43^{\prime} \mathrm{N}, 77^{\circ} 72^{\prime} \mathrm{E}\right.$ and $915 \mathrm{~m}$ above sea level), India, during July-September 2017. The experiment was conducted on 2-weeks-old seedlings, planted in red sandy loam soil. Ten-days-old cabbage (cv. Saint) seedlings were procured from the local nursery and transplanted by following ridges and furrow method. A recommended dose of fertilizer $(25 \mathrm{~kg} \mathrm{~N} ; 150 \mathrm{~kg}$ P; $25 \mathrm{~kg}$ K) was applied as a basal dose. One month after planting, a nitrogenous fertilizer was applied $(50 \mathrm{~kg})$ during the earthing up operation $(50 \mathrm{~kg})$. Crop was irrigated through drip irrigation. During the experimental period, except DBM, no other pest species were observed on cabbage plants. Hence, the management strategies were based on the occurrence of DBM and suitable biocontrol inputs that were integrated with farmer practices. The experiment was conducted in a cabbage field of $2000 \mathrm{~m}^{2}$, with a plant spacing of $(45 \times 60 \mathrm{~cm})$. The experimental layout was a randomized complete block design with two treatments. There were 15 replicates (blocks of $\left.66 \mathrm{~m}^{2}\right)$ per treatment $\left(1000 \mathrm{~m}^{2}\right)$ and approximate 245 plants per replicate (a total of 3675 plants per treatment). To estimate the larval populations of DBM, three plants were selected randomly within each block. By thorough inspection, the number of larvae/plant was counted and the population density of larvae was estimated. The number of holes on the leaves caused by DBM was also counted. To estimate the number of holes/plant, the inner leaves of cabbage were observed, excluding the old leaves. However, to estimate the percent head damage, 10 plants were randomly selected and observed for the damage due to larval scrapping and also feeding holes made by larvae on the leaves. Based on healthy and damaged heads, the percentages of head damage were calculated.

The release of $T$. chilonis was initiated 15 days after transplanting, then parasitoids were released weekly at $9.30 \mathrm{a} . \mathrm{m}$. (at the rate of 100,000 parasitized eggs ha ${ }^{-1}$ ). A total of six releases were made at weekly intervals. The parasitoids were released immediately after observing about (5\%) emergence in the laboratory. The trichocards, each having approximate 15,000 parasitized eggs, were cut into small pieces ( 16 bits; $4 \times 1.5 \mathrm{~cm}$ ) before release. Thus, for an area of $\left(2000 \mathrm{~m}^{2}\right.$ a total of 24 pieces) were used ( 3 tricho-cards). These small pieces of trichocards were stapled to the lower surfaces of cabbage leaves and were uniformly distributed in the field. Then, 
the liquid formulation of B. thuringiensis (NBAIR BtG4) was applied after third and fifth releases of parasitoids (10 and 20 days after transplanting) depending on the larval population. A liquid $B t \mathrm{G} 4$ formulation was thoroughly mixed, using a sticker (gum acacia 1\%) in $350 \mathrm{l}$ capacity tank containing $300 \mathrm{l}$ of tap water. Then, this $B$. thuringiensis (NBAIR BtG4) suspension was sprayed on cabbage plants at $5.00 \mathrm{pm}$ by using tractor-drawn Horizontal Triplex Power (HTP) sprayer. Insecticidal application was carried out by farmers at 15 days after transplantation. Insecticides were applied through tractor-drawn HTP sprayer with the recommended concentration of each insecticide either single application or in combination in a similar volume of water.

The comparison was between DBM larval populations, holes on the leaves, and the percentage of damaged heads. These estimations were monitored at 15, 30, and 45 days after treatment (DAT) with farmer's practice and biocontrol-based IPM. The details of these both treatments are given in (Table 1). The effect of treatments on cabbage yield was estimated and recorded and the cost benefit of biocontrol-based IPM and farmer's practice was calculated.

\section{Statistical analysis}

The arcsine transformation was used to normalize the percentage of damage before an ANOVA was conducted. Analysis was undertaken on the transformed data and untransformed means \pm SE. All data were analyzed using PROC GLM (SAS version 9.3; SAS Institute 2011). Biocontrol agents' rates, insecticides' doses, and time effects, and their interactive effects on the number of larvae plant ${ }^{-1}$, holes' number plant ${ }^{-1}$, and percentages of damaged heads were estimated, using PROC GLM (SAS version 9.3; SAS Institute 2011). When ANOVA was significant, comparisons of relevant means were made, using Tukey's post hoc significance test at a significance level of $5 \%$. The cost benefit of both treatments was estimated based on Bt (NBAIR BtG4), T. chilonis and insecticides' applications. Average heads' yield was calculated in $\mathrm{kg} \mathrm{ha}^{-1}$. The cost of the treatments was estimated based on the cost of production of $T$. chilonis MITs, $B t$ (NBAIR BtG4), and retail price of insecticides. Net profit was estimated based on the income of cabbage yield (USD\$ 0.22 per $\mathrm{kg}$ ) and the cost $\mathrm{ha}^{-1}$ from both the treatments.

\section{Results and discussion}

In order to determine the efficacy of the biological control agents integrated with reduced number insecticidal application in the management of DBM in comparison with farmer's practice, it is important to consider the level of pest reduction, the reduction in crop damage, and net profit to encourage the farming community.

\section{Reduction in DBM larval population}

The number of DBM larvae were significantly $(F=41.55$, $\mathrm{df}=1,84, P<0.0001)$ reduced in the 2 treatments. In biocontrol-based IPM field, the number of larvae was significantly $(P<0.05)$ lower compared to farmer's practice (Fig. 1). Analysis of variance showed that there was insignificant interaction between the treatments and

Table 1 IPM treatments and their application methods for controlling DBM in cabbage

\begin{tabular}{llll}
\hline Treatments & Treatment details & $\begin{array}{l}\text { Number of } \\
\text { application }\end{array}$ & Application methods \\
\hline Biocontrol-based IPM (T1) & Trichogramma chilonis MITs-NBAll-MP-Tri 13 & 6 & Stapling the Tricho bits at under surface of leaves \\
& Bacillus thuringiensis-NBAIR BtG4 & 2 & Foliar spray \\
& Chlorantraniliprole & 1 & Foliar spray \\
& Spinosad & 1 & Foliar spray \\
& Spinosad + Fenpropathrin & 1 & Foliar spray \\
& Chlorantraniliprole & Foliar spray \\
& Emamectin benzoate + Dichlorvos & 1 & Foliar spray \\
Insecticide-treated farmers' practice (T2) & Chlorantraniliprole & 1 & Foliar spray \\
& Emamectin benzoate + Dichlorvos & 1 & Foliar spray \\
Chlorantraniliprole & 1 & Foliar spray \\
Emamectin benzoate + Dichlorvos & 1 & Foliar spray \\
Spinosad + Chlorantraniliprole & 1 & Foliar spray \\
Thiodicarb & 1 & Foliar spray \\
Spinosad + Chlorantraniliprole & 1 & Foliar spray \\
Indoxacarb & 1 & Foliar spray \\
Spinosad + Chlorantraniliprole & 1 & Foliar spray \\
\hline
\end{tabular}




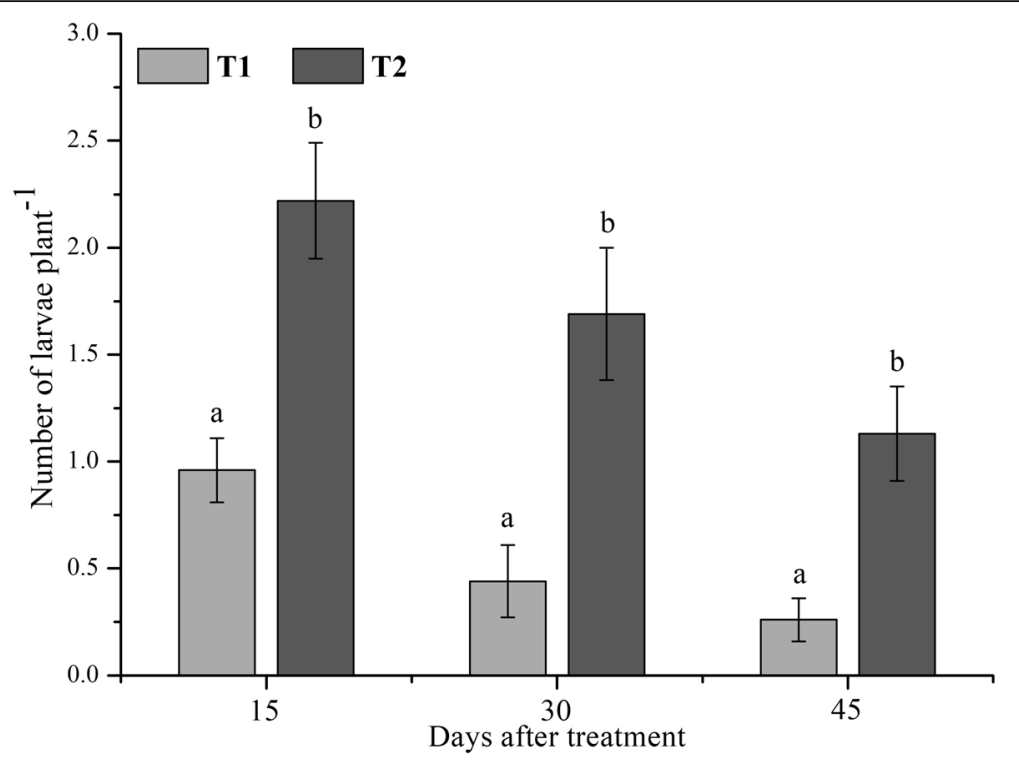

Fig. 1 Effect of biocontrol-based IPM and farmers' practice on larval reduction of DBM in cabbage at 15, 30, and 45 days after treatment. Different letters on the top of error bars indicate statistically different values for different treatments using Tukey's test $(P<0.05)$. Bars $=s t a n d a r d$ error, $\mathrm{T} 1=$ biocontrol-based IPM, T2 = farmers' practice

days $(F=0.54, \mathrm{df}=1,84, P<0.5854)$. It was also found that the number of larvae was significantly $(P<0.05)$ reduced in 30 and 45 days after treatment (DAT) than at 15 DAT $(0.44,0.26,0.96$ larvae at 30, 45, and 15 DAT, respectively). These results indicated that those eggs escaped from parasitism by $T$. chilonis might have hatched and showed less susceptibility to insecticides at 15 DAT. DBM has been difficult to be controlled with synthetic insecticides in many regions of the world because larvae quickly developed resistance to the insecticides (Kianmatee and Ranamukhaarachchi 2007). Another research on DBM showed that larvae were also less susceptible to insecticides, including recently introduced diamides and other groups of compounds (Wang and Wu 2012 and IRAC 2017). Moreover, the parasitoids released to control DBM eggs on the plant is a random process, and the percentage of parasitism sometimes will not always be higher on plants near the release point (Miura 2003). Therefore, frequent mass releases of $T$. chilonis were carried out to control the population of DBM for a wide coverage resulting in fewer larval population in 30 and 45 DAT. Under field conditions, the parasitism percent with $T$. chilonis to the eggs of DBM ranged from 42 to $57 \%$ on cabbage and 77.06 to $94.87 \%$ on Indian mustard, when used as a trap crop in cabbage (Yadav et al. 2001). Bond and Boyce (1971) demonstrated that when viable DBM eggs on cabbage leaves were dipped in solutions of Bt kurstaki $\left(\right.$ Vectobac $\left.^{\circ}\right)$, mortality increased with increase in Btk concentration. Apart from releasing T. chilonis, Bt (NBAIR BtG4) was sprayed after the third and fifth releases of parasitoid. Therefore, the decreased number of larval population occurred at 30 and 45 DAT. Studies confirming the high field efficacy of $B t$ against the larvae of DBM were reported by Singh et al. 2015 and Stemele 2017. These former conclusions agree with those of the present study which showed decrease in DBM population after spraying the $B t$ (NBAIR BtG4).

\section{Number of holes on leaves/plant}

The mean number of holes on cabbage leaves were 7.08 per plant in biocontrol-based IPM approach compared to the insecticide-treated farmer practice, $(17.72$ holes per plant) $(F=78.61, \mathrm{df}=1,84, P<0.0001)$. The difference in the mean number of holes on cabbage leaves/ plant between the 2 treatments, was insignificant at 15 and 30 DAT, whereas, at 45 DAT the numbers of holes were significantly lower $(2.21$ holes per plant $)(P<0.05)$ in biocontrol-based IPM approach (Fig. 2). Analysis of variances revealed that there was insignificant interaction between treatments and days. In the present study, irrespective of the treatment, higher numbers of holes were observed at 15 DAT. However, significantly $(P<0.05)$ lower number of holes per plant were recorded in biocontrol-based IPM after 45 DAT (2.21 plants $^{-1}$ ). The present data showed that in both treatments, the number of holes on cabbage leaves was significantly reduced at 45 DAT. The differences in the larval reduction at 15 and 45 DAT could explain why cabbage plants showed significantly higher leaf damage due to DBM attack at 15 DAT in both treatments. The obtained results indicated that the numbers of holes on 


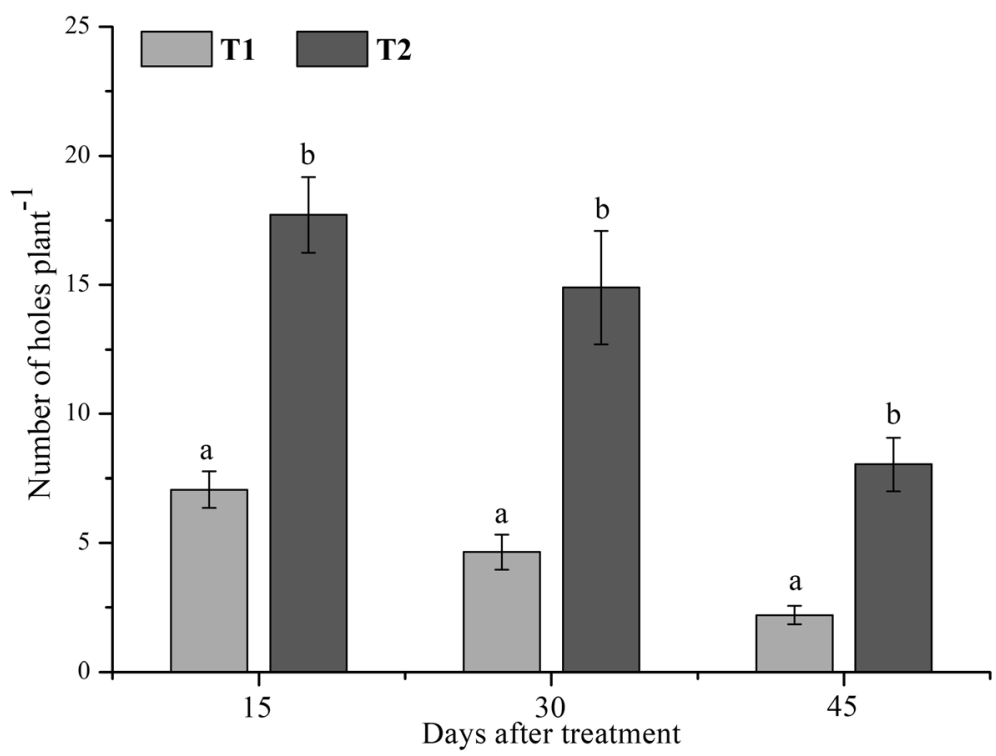

Fig. 2 Effect of biocontrol-based IPM and farmers' practice on a number of holes on cabbage leaves per plant by DBM at 15, 30, and 45 days after treatment. Different letters on the top of error bars indicate statistically different values for different treatments using Tukey's test $(P<0.05)$. Bars $=$ standard error, $\mathrm{T} 1=$ biocontrol-based IPM, $\mathrm{T} 2=$ farmers' practice

cabbage leaves were also lower (8.04) in the farmers' insecticide practice. Similarly, Freddy (2011) reported that the leaf damage was significantly lower in the fields treated with insecticides than in non-treated. Motoyama et al. (1990) advised that the use of insecticides for control of DBM for longer period is not a good practice because DBM can develop resistance very quickly to insecticides. Integration of biological control treatment(s) with other control methods become necessary for pests' suppression, and this control can be sustained continuously for a longer period (Lim 1992). Therefore, in the present study, when integrated biological control agents with a reduced number of insecticidal sprays were practiced, they gave a very good control of DBM. Similarly, Reddy and Guerrero (2000) reported a decrease in leaves damage continuously after 12 weeks of transplanting in the IPM-based treatment integrated with natural enemies and $B t$.

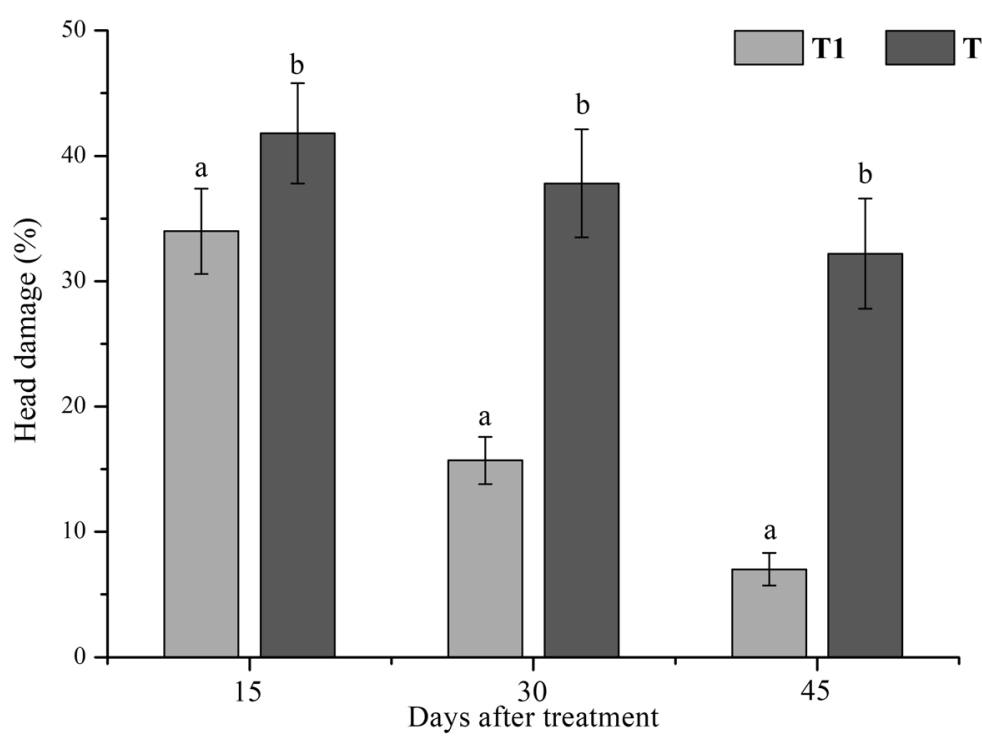

Fig. 3 Effect of biocontrol-based IPM and farmers' practice on percentage head damage of cabbage at 15, 30, and 45 days after treatment. Different letters on the top of error bars indicate statistically different values for different treatments using Tukey's test $(P<0.05)$. Bars $=$ standard error, T1 = biocontrol-based IPM, T2 = farmer's practice 
Table 2 Cost-benefit of biocontrol-based IPM practices and insecticide-treated farmers' practice for controlling DBM in cabbage

\begin{tabular}{|c|c|c|c|c|c|c|}
\hline Treatments & Inputs & Rates ha ${ }^{-1}$ & $\begin{array}{l}\text { Cost of production } \\
\left(\text { US\$ ha }{ }^{-1}\right)^{a}\end{array}$ & $\begin{array}{l}\text { Yield } \\
\left(\mathrm{kg} \mathrm{ha}^{-1}\right)\end{array}$ & $\begin{array}{l}\text { Income } \\
(\text { US\$ })^{\mathrm{b}}\end{array}$ & $\begin{array}{l}\text { Net profit } \\
(U S \$)^{c}\end{array}$ \\
\hline \multirow[t]{7}{*}{ Biocontrol-based IPM } & T. chilonis & $100,000 \mathrm{ha}^{-1}$ & 55.8 & 23,590 & 5413.9 & 5124.8 \\
\hline & B. thuringiensis & 301 & 91.9 & & & \\
\hline & Chlorantraniliprole & $75 \mathrm{ml}$ & 18.2 & & & \\
\hline & Spinosad & $187.5 \mathrm{ml}$ & 54.8 & & & \\
\hline & Spinosad + Fenpropathrin & $93.5+375 \mathrm{ml}$ & 30.3 & & & \\
\hline & Chlorantraniliprole & $75 \mathrm{ml}$ & 18.2 & & & \\
\hline & Emamectin benzoate + Dichlorvos & $150 \mathrm{~g}+562.5 \mathrm{ml}$ & 19.9 & & & \\
\hline \multirow[t]{9}{*}{ Insecticide-treated farmers' practice } & Chlorantraniliprole & $75 \mathrm{ml}$ & 18.2 & 12,920 & 2965.1 & 2749.3 \\
\hline & Emamectin benzoate + Dichlorvos & $150 \mathrm{~g}+562.5 \mathrm{ml}$ & 19.9 & & & \\
\hline & Chlorantraniliprole & $75 \mathrm{ml}$ & 18.2 & & & \\
\hline & Emamectin benzoate + Dichlorvos & $150 \mathrm{~g}+562.5 \mathrm{ml}$ & 19.9 & & & \\
\hline & Spinosad + Chlorantraniliprole & $93.75+37.5$ & 36.5 & & & \\
\hline & Thiodicarb & $1125 \mathrm{~g}$ & 14.0 & & & \\
\hline & Spinosad + Chlorantraniliprole & $93.75+37.5 \mathrm{ml}$ & 36.5 & & & \\
\hline & Indoxacarb & $265.5 \mathrm{ml}$ & 16.1 & & & \\
\hline & Spinosad + Chlorantraniliprole & $93.75+37.5$ & 36.5 & & & \\
\hline
\end{tabular}

Exchange rate used for conversion INR to US Dollar: US\$ $1=65.15$ INR (5 October 2017)

${ }^{a}$ Cost for the $T$. chilonis and Bt was estimated based on cost of production and retail price of the insecticides at 2 July 2017

${ }^{\mathrm{b}}$ Local purchase price of the cabbage was (US\$ $0.23 \mathrm{~kg}^{-1}$ ) on 5 October 2017

${ }^{c}$ Net profit was calculated based on the only income of cabbage and the cost per hectare from different treatments

\section{Percentages of cabbage damaged heads by DBM}

It was found that application of biocontrol-based IPM reduced significantly, the percentage of damaged heads than farmers' practice $(F=54.45, \mathrm{df}=1,84, P<0.0001)$ (Fig. 3$)$. The percentage of head damage was lower as the trial period progressed in the 2 treatments $(F=19.60, \mathrm{df}=2$, 84, $P<0.0001$ ) (Fig. 3). Significant interaction was also found between treatments and days $(F=5.82, \mathrm{df}=2,84, P$ $=0.0043)$. The percentage head damage was highest $(34 \%)$ in biocontrol-based IPM at 15 DAT whereas it was lowest (7\%) at 45 DAT. However, in the farmers' practice, highest percentage head damage was observed (41.83\%) at 15 DAT and lowest being (32.22\%) at 45 DAT.

\section{Crop yield}

The cost for using biocontrol-based IPM for the management of DBM was (USD $289.1 \mathrm{ha}^{-1}$ ), while in case of farmers' practice, it was (USD $215.7 \mathrm{ha}^{-1}$ ). Cabbage yields were $23,590.0$ and $12,920.0 \mathrm{~kg} \mathrm{ha}^{-1}$ and net profit was USD 5124.8 and $2749.3 \mathrm{ha}^{-1}$, respectively (Table 2).

\section{Conclusions}

The present study showed that integration of biological control agents $T$. chilonis and B. thuringiensis (NBAIR $B t G 4$ ) with a reduced number of insecticidal sprays was able to manage the DBM efficiently in the cabbage fields and increased the obtained yield.

\section{Acknowledgements}

The authors are grateful to the Indian Council of Agricultural Research, New Delhi, India, the Director, ICAR-National Bureau of Agricultural Insect Resources and Project Coordinator AICRP-BC, Bengaluru, India, for the facilities provided for conducting the study.

\section{Authors' contributions}

First and fourth authors designed the research. All authors conducted the experiments. Six and seventh authors mass produced the biocontrol agents. First and eighth authors analyzed the data and wrote the manuscript. All the authors read and approved the final manuscript.

\section{Funding}

This research work was financially supported by the Indian Council of Agricultural Research, New Delhi, All India Coordinated Research Projects-Biological control, and ICAR-National Bureau of Agricultural Insect Resources, Bengaluru, India.

\section{Availability of data and materials}

All data are available at the end of the article and the materials used in this work are of high quality and grade.

\section{Ethics approval and consent to participate}

All experimental works were approved by ICAR-National Bureau of Agricultural Insect Resources, Bengaluru, India, under the umbrella of AICRP-Biological Control project.

\section{Consent for publication}

The agreement of publication was taken, and as a corresponding author, I confirm that.

\section{Competing interests}

The authors declare that they have no competing interests.

\section{Author details}

${ }^{1}$ Division of Germplasm Collection and Characterization, ICAR-National Bureau of Agricultural Insect Resources, P. B. No. 2491, H. A. Farm Post, 
Bellary Road, Bengaluru 560 024, India. ${ }^{2}$ ICAR- National Bureau of Agricultural Insect Resources, Bengaluru 560 024, India.

Received: 6 December 2018 Accepted: 20 May 2019

Published online: 28 May 2019

\section{References}

Asokan R, Mohan KS (1996) Effect of commercial formulations of Bacillus thuringiensis Berliner on yield of cabbage. Insect Environ 2:58-59

Bond RP, Boyce CB (1971) The Thermostable Exotoxin of Bacillus thuringiensis. Shell Research Limited, Milstead Laboratory of Chemical Enzymology, Kent, England

Freddy MO (2011) The role of predators, parasitoid and insecticides. Doctoral thesis, Swedish University of Agricultural Sciences, Uppsala, p 71

Guo M, Zhu D, Li L (1999) Selection of Trichogramma species for controlling the diamondback moth Plutella xylostella (L). Entomologia sinica 6:187-192

IRAC (2017) http://www.irac-online.org/pests/plutella-xylostella. Accessed 7 Sept 2017

Jalali SK, Venkatesan T, Murthy KS, Ojha R (2016) Management of Helicoverpa armigera (Hübner) on tomato using insecticide resistance egg parasitoid, Trichogramma chilonis Ishii in farmers' field. Indian J Hort 73:611-614

Justin CGL, Rabindra RJ, Jayaraj S (1990) Bacillus thuringiensis Berliner and some insecticides against the diamondback moth, Plutella xylostella (L.) on cauliflower. J Biol Control 4:40-43

Kianmatee S, Ranamukhaarachchi S (2007) Combining pest repellent plants and biopesticides for sustainable pest management in Chinese kale. J Asia Pac Entomol 10:69-74

Lim GS (1992) Integrated pest management of diamondback moth: practical realities. In: Talekar NS (ed) Management of diamondback moth and other crucifer pests: Proceedings of the Second International Workshop. Asian Vegetable Research and Development Center Shanhua, Taiwan, pp 565-576

Lingappa S, Basavanagoud K, Kulkarni KA, Patil RS, Kambrekar DN (2004) Threat to vegetable production by diamondback moth and its management strategies. In: Mukerji KG (ed) Vol. 1. Fruit and vegetable diseases. Kluwer Academic Publishers, Netherlands, pp 357-396

Miura K (2003) Suppressive effect of the egg parasitoid Trichogramma chilonis Ishii (Hymenoptera: Trichogrammatidae) on the population density of the diamondback moth. Appl Entomol Zool 38:79-85

Motoyama N, Suganuma T, Maekoshi Y (1990) Biochemical and physical characteristics of insecticide resistance in diamondback moth. In: Talekar NS (ed) Diamondback moth and other crucifer pests: Proceeding of the Second International Workshop, 11-15 December 1992. Asian Vegetable Research and Development Center, Shanhua, Taiwan, pp 411-418

Nagarkatti S, Jayanth KP (1982) Population dynamics of major insect pests of cabbage and of their natural enemies in Bangalore district (India). In: Proceedings of the international conference on plant protection in the tropics, 1-4 March, 1982, Kuala Lumpur, pp 325-347

NHB (2016) Second advance estimate of area and production of horticulture crops (2016-2017). National Horticulture Board. p.6. http://nhb.gov.in/areapro/Areapro16-17.pdf. Accessed 24 Aug 2017.

Ramya SL, Venkatesan T, Murthy KS, Jalali SK, Abraham V (2016) Field-evolved insecticide resistance and biochemical validation of enzyme activities in diamondback moth, Plutella xylostella. Indian J Plant Protec 44:9-15

Reddy GVP, Guerrero A (2000) Pheromone-based integrated pest management to control the diamondback moth Plutella xylostella in cabbage fields. Pest Manag Sci 56:882-888

Sarfraz M, Keddie AB, Dosdall LM (2005) Biological control of the diamondback moth, Plutella xylostella: a review. Biocontrol Sci Techn 15:763-789

SAS Institute (2011) SAS version 9.3 system options: reference, $2^{\text {nd }}$ edition. SAS Institute, Cary

Shelton AM (2004) Management of the diamondback moth: deja vu all over again? In: Endersby NM, Ridland PM (eds) The management of diamondback moth and other crucifer pests, pp 3-8. Proceedings of the fourth international workshop Diamondback moth, 26-29 November 2001, Melbourne, Australia

Singh Kl, Debbarma A, Singh HR (2015) Field efficacy of certain microbial insecticides against Plutella xylostella Linnaeus and Pieris brassicae Linnaeus under cabbage-crop-ecosystem of Manipur. J Biol Control 29:194-202

Singh SP, Jalali SK (1993) Evaluation of trichogrammatids against P. xylostella. Trichogramma News 7:27
Singh SP, Jalali SK, Venkatesan T (2000) Susceptibility of diamondback moth and its egg parasitoid to a new Bt formulation. Pest Manag Hort Ecosyst 6:114-117

Stemele MA (2017) Comparative effects of a selective insecticide, Bacillus thuringiensis var. kurstaki and the broad-spectrum insecticide cypermethrin on diamondback moth and its parasitoid Cotesia vestalis (Hymenoptera; Braconidae). Crop Prot 101:35-42

Talekar NS, Shelton AM (1993) Biology, ecology and management of the diamondback moth. Annu Rev Entomol 38:275-301

Wang X, Wu Y (2012) High levels of resistance to chlorantraniliprole evolved in field populations of Plutella xylostella. J Econ Entomol 105:1019-1023

Yadav DN, Anand J, Devi PK (2001) Trichogramma chilonis on Plutella xylostella (Lepidoptera: Plutellidae) in Gujarat. Indian J Agric Sci 71:69-70

\section{Publisher's Note}

Springer Nature remains neutral with regard to jurisdictional claims in published maps and institutional affiliations.

\section{Submit your manuscript to a SpringerOpen ${ }^{\circ}$ journal and benefit from:}

- Convenient online submission

- Rigorous peer review

- Open access: articles freely available online

High visibility within the field

- Retaining the copyright to your article

Submit your next manuscript at $\boldsymbol{\nabla}$ springeropen.com 